\title{
ANALISIS INTENSI WAKIF GEN Y DALAM GERAKAN DIGITAL BERWAKAF UANG ATAU MELALUI UANG DI INDONESIA
}

\author{
ANALYSIS OF THE INTENTION OF GEN Y WAQF IN THE DIGITAL MOVEMENT OF \\ MONEY OR THROUGH MONEY IN INDONESIA
}

\author{
Meutia Rahma $^{*) 1}$, Mukhamad Najib ${ }^{* *)}$, Imam Teguh Saptono ${ }^{*}$ \\ ${ }^{*}$ Sekolah Bisnis, IPB University \\ Jl. Pajajaran Bogor 16151, Indonesia \\ ${ }^{* *}$ Departemen Manajemen, Fakultas Ekonomi dan Manajemen, IPB University \\ Jl. Agatis Kampus Dramaga, Bogor 16880, Indonesia
}

\begin{abstract}
The purpose of this study is to identify the characteristics of wakif gen $Y$ in waqf activities and analyze what factors influence the intention of wakif gen $Y$ in the use of digital payment technology to encourage the digital movement of cash waqf and waqf through money in Indonesia. In general, this research is conducted qualitatively through descriptive and quantitative analysis through structural equation modeling (SEM) analysis. The number of samples studied was 160 wakif gen $Y$. The results showed that all the variables studied were performance expectancy (PE), effort expectancy (EE), social influence (SI), facilitating condition $(F C)$, hedonic motivation (HM), price value $(P V)$, habit (HT), and perceived security (PS) have a significant influence on behavioral intention (BI) wakif gen $Y$ in encouraging the use of digital payment technology for cash waqf payments. The biggest factor is habit with a value of t count 12.93, and the standardized coefficient is 0.59. The next factor that has a significant effect on priority is performance expectancy (PE).
\end{abstract}

Keywords: digital payment, intention, cash waqf, waqf through money, wakif gen Y

\begin{abstract}
Abstrak: Tujuan penelitian ini adalah mengidentifikasi karakteristik dari wakif gen Y dalam kegiatan berwakaf dan menganalisis faktor-faktor yang memengaruhi intensi wakif gen $\mathrm{Y}$ dalam pemanfaatan teknologi digital payment serta implikasi manajerial bagi lembaga nazhir untuk mendorong gerakan digital berwakaf uang atau wakaf melalui uang di Indonesia. Secara umum penelitian ini dilakukan secara kualitatif melalui analisis deskriptif dan kuantitatif melalui analisis structural equation modeling (SEM). Jumlah sampel yang diteliti adalah 160 wakif gen Y. Hasil penelitian menunjukkan bahwa keseluruhan variabel yang diteliti, yaitu performance expectancy (PE), effort expectancy (EE), social influence (SI), facilitating condition ( $\mathrm{FC})$, hedonic motivation $(\mathrm{HM})$, price value (PV), habit (HT), dan perceived security (PS) memiliki pengaruh signifikan terhadap behavioral intention (BI) wakif gen $\mathrm{Y}$ dalam mendorong penggunaan teknologi digital payment untuk pembayaran wakaf uang. Faktor yang paling besar adalah kebiasaan (habit) dengan nilai t hitung 12.93, dan besar koefisien standardized adalah 0,59 . Faktor selanjutnya yang berpengaruh signifikan berdasarkan prioritas adalah performance expectancy (PE).
\end{abstract}

Kata kunci: digital payment, intensi, wakaf uang, wakaf melalui uang, wakif gen $\mathrm{Y}$

\footnotetext{
${ }^{1}$ Corresponding author:

Email: thesis.meutia@gmail.com
} 


\section{PENDAHULUAN}

Ascarya (2016) mengatakan bahwa perkembangan ekonomi dan keuangan Islam tidak hanya mencakup aspek komersial tetapi juga aspek sosial (seperti zakat, infak, wakaf, dan keuangan mikro), dimana kedua aspek tersebut tidak dapat terpisahkan. Oleh karena itu, integrasi antara sektor sosial dan komersial tidak hanya dapat mengurangi kemiskinan, meningkatkan kesejahteraan sosial-ekonomi dan meningkatkan inklusi keuangan holistik, tetapi juga dapat meningkatkan stabilitas sistem keuangan.

Wakaf adalah salah satu instrumen yang dapat merealisasikan tujuan tersebut dalam memberikan keuntungan sosial ekonomi bagi masyarakat. Menurut Suganda (2014) kata wakaf (jamaknya: awqaf) dalam terminologi hukum Islam didefinisikan sebagai suatu tindakan penahanan dari penggunaan dan penyerahan aset dimana seseorang dapat memanfaatkan atau menggunakan hasilnya untuk tujuan amal, sepanjang barang tersebut masih ada. Wakaf memiliki nilai amalan yang akan terus mengalir bagi pemberi wakaf atau yang disebut dengan wakif meskipun sudah meninggal dunia. Dalam hal ini wakaf merupakan sedekah dari individual yang pokoknya tidak boleh habis. Pemahaman terhadap wakaf pada umumnya masih dipahami dalam lingkup yang masih sempit, yaitu sebagai penyedia infrasturktur bagi aktivitasaktivitas nirlaba religius, seperti pembangunan masjid, madrasah, dan pemakaman.

Pemanfaatan wakaf secara lebih luas dapat juga dimanfaatkan untuk kepentingan investasi pada sektor komersial dan infrasturktur yang dapat menghasilkan laba, misalnya lahan wakafdidirikangedung perkantoran yang memiliki unit-unit yang dapat disewakan. Laba yang dihasilkan dari dari penyewaan unit kantor dapat didukung untuk mendukung operasional sektor nirlaba, misalkan untuk beasiswa para santri di pesantren atau bantuan bea premi BPJS bagi pasien di rumah sakit dhuafa. Pada akhirnya, apabila hal tersebut dapat dijalankan maka akan dapat memberikan manfaat fiskal. Manfaat fiskal disini adalah layanan publik yang biasa didapatkan dari pemerintah, seperti pembangunan infrastruktur dan layanan sosial dapat dijalankan oleh masyarakat melalui wakaf. Hal ini tentu saja baik bagi anggaran negara karena belanja pemerintah telah disubstitusi oleh aktivitas filantropi berupa wakaf.
Optimalisasi wakaf di Indonesia apabila dikerjakan secara maksimal maka akan mencapai titik balik kebangkitan ummat. Menurut Badan Wakaf Indonesia (BWI) dalam Komite Nasional Keuangan Syariah (KNKS) 2019, potensi aset wakaf di Indonesia yaitu sekitar Rp2.000 triliun dengan luas tanah wakaf mencapai 420 ribu hektar dan potensi wakaf uang mencapai Rp377 trilliun dari realisasi dana wakaf uang yang terkumpul per 2017 hanya mencapai Rp199 Miliar. Nilai ini menjanjikan potensi bisnis yang tidak dapat diabaikan.

Potensi dana wakaf tersebut juga dapat dioptimalkan dengan adanya penghimpunan dana yang dikelola secara institusional oleh nazhir yang ditunjuk oleh pemerintah. Hal ini dikarenakan sebagian besar wakif masih melakukan pembayaran wakaf kepada kepada nazhir perorangan yaitu sebanyak 55\% (Survey Indeks Literasi Wakaf, 2020 dalam BWI, 2020). KNKS (2019) menjelaskan bahwa penghimpunan potensi dana wakaf secara institusional di Indonesia dapat dimaksimalkan dengan adanya pemanfaatan inovasi khususnya di bidang teknologi pada era revolusi industri 4,0. Hal ini sejalan dengan kebijakan yang telah dirubah oleh BWI terkait peraturan dimana wakif yang seharusnya berhadapan langsung dengan nazhir pada saat akad bisa digantikan dengan sistem elektronik sehingga ikrar wakaf pun bisa dilakukan secara elektronik.

Pada era revoulsi digital seperti sekarang ini, perkembangan teknologi dan informasi akan mampu memberikan kontribusi positif terhadap peningkatan program wakaf uang/melalui uang. Menurut Berakon et al. 2017, wakaf uang atau sering disebut dengan wakaf tunai adalah wakaf yang dilakukan seseorang, kelompok orang dan lembaga atau badan hukum dalam bentuk uang tunai. yang termasuk kedalam pengertian uang dalah surat-surat berharga, seperti saham, cek dan lainnya. Menurut Antonio (2002), nominal uang yang diwakafkan dengan wakaf uang bisa bervariasi sehingga pemilik dana yang terbatas sudah dapat mulai berwakaf tanpa harus menunggu menjadi golongan menengah ke atas terlebih dahulu. Sedangkan wakaf melalui uang menurut Fahruroji (2019) adalah wakaf dengan memberikan uang untuk dibelikan/dijadikan harta benda tidak bergerak atau harta benda bergerak sesuai yang dikehendaki wakif atau program/proyek yang ditawarkan kepada wakif, baik untuk keperluan sosial maupun produktif/investasi. 
Kemajuan teknologi telah mengubah transformasi sistem pembayaran masa kini. Trihasta et al. (2008) menjelaskan bahwa pembayaran secara umum dapat diartikan sebagai pemindahan sejumlah uang dari si pembayar ke penerima. Jika sebelumnya masyarakat menggunakan media uang tunai untuk membeli dan membayar sesuatu, kini banyak orang di zaman sekarang yang sudah meninggalkan transaksi tunai dan beralih ke transaksi non-tunai atau cashless. Didik (2019) menjelaskan bahwa bentuk transaksi seperti ini lebih dikenal dengan digital payment atau pembayaran digital. Tren inilah yang seharusnya dapat diadaptasi untuk memaksimalkan gerakan berwakaf uang maupun melalui uang secara digital.

Perkembangan teknologi informasi saat ini di Indonesia, hampir lebih dari sebagian dimotori oleh anak muda, yang mayoritasnya dipimpin oleh generasi milenial. Deloitte Indonesia (2019) menjelaskan bahwa saat ini prosentase milenial di Indonesia merupakan jumlah terbesar $(33,75 \%)$, diikuti dengan jumlah generasi $\mathrm{Z}(29,23 \%)$, generasi $\mathrm{X}(25,74 \%)$, dan yang paling sedikit adalah generasi baby boomers dan veteran (11,27\%). Faktanya, menurut IDN Research Insitute dalam Deloitte Indonesia (2019), lebih dari 94,4\% Gen Y saat ini telah terkoneksi dengan internet dan akses media yang paling banyak di konsumsi oleh Gen $\mathrm{Y}$ adalah televisi (97\%) diikuti dengan media digital $(54,5 \%)$. Hal ini menunjukkan bahwa internet menjadi kebutuhan utama bagi para millenial.

Lancaster dan Stillman (2002) dalam BPS (2018) menyebutkan bahwa generasi $\mathrm{Y}$ dikenal dengan sebutan generasi Millenial atau Milenium. Generasi Y ini sangat diharapkan sebagai agen dalam perubahan yang dapat memengaruhi pasar baik di bidang ekonomi maupun bidang politik selama beberapa tahun ke depan. Generasi Y berpotensi memegang kendali atas roda pembangunan khususnya di bidang perekonomian yang diharapkan akan mampu membawa bangsa Indonesia menuju ke arah pembangunan yang lebih maju dan dinamis. Intinya, generasi Y adalah modal besar untuk mewujudkan kemandirian bangsa dalam segala aspek. Sebagai modal besar pembangunan suatu bangsa, diharapkan generasi Y memiliki potensi lebih unggul dibandingkan generasi-generasi sebelumnya. Berbagai karakteristik yang dimiliki oleh generasi Y merupakan modal untuk berkompetisi dalam bonus demografi Indonesia pada tahun 2020-2030, terutama dalam bidang wakaf. Lembaga nazhir dapat mengoptimalkan keberadaan generasi Y untuk mendukung peningkatan potensi wakaf uang di Indonesia melalui pemanfaatan layanan digital yang terjadi saat ini. Layanan digital wakaf diharapkan dapat diimplementasikan secara tepat dengan membidik sasaran di Indonesia kepada generasi Y.

Sehubungan dengan hal tersebut, intensi terhadap penggunaan teknologi digital payment oleh wakif gen Y untuk berwakaf uang/melalui uang menjadi hal yang sangat penting untuk dikaji dalam penelitian ini. Salah satu model teori yang digunakan terhadap penerimaan teknologi adalah model Unified Theory of Acceptance and Use of Technology (UTAUT) 2 oleh Venkatesh et al. (2012), yang merupakan pengembangan dari model UTAUT. Berdasarkan model UTAUT yang pertama kali dikembangkan oleh Venkatesh et al. (2003) terdapat empat variabel kunci yang memengaruhi intensi perilaku maupun penggunaan teknologi yaitu performance expectancy (harapan kinerja), effort expectancy (harapan usaha), social influence (pengaruh sosial), dan facilitating condition (kondisi fasilitasi). Selanjutnya Venkatesh et al. (2012) melakukan penyesuaian variabel dari model UTAUT terhadap penerimaan dan penggunaan teknologi bagi konsumen dengan menambah tiga variabel yaitu hedonic motivation (motivasi hedonis), price value (nilai harga), dan habit (kebiasaan). Selain ketujuh variabel tersebut dirasa perlu menambahkan faktor keamanan dirasakan (perceived security) sebagai pertimbangan atas penerimaan teknologi. Hal ini disampaikan oleh Junadi dan Sfenrianto (2015) pada model Factors Influencing Consumer's Intention to Use e-Payment System.

Penelitian ini bertujuan mengidentifikasi karakteristik dari wakif gen Y dalam kegiatan berwakaf. Selanjutnya, menganalisis faktor-faktor apa saja yang memengaruhi intensi wakif gen $\mathrm{Y}$ dalam pemanfaatan teknologi digital payment untuk mendorong gerakan berwakaf uang/melalui uang secara digital di Indonesia.

\section{METODE PENELITIAN}

Penelitian ini dilakukan di Indonesia yang dimulai pada bulan Agustus 2020 sampai September 2020. Sumber data yang digunakan dalam penelitian ini meliputi data primer dan data sekunder. Data primer diperoleh dari penyebaran survey secara online melalui google form pada tautan bit.ly/wakafdigital untuk dapat menjangkau responden yang lebih luas di wilayah Indonesia. Data 
sekunder, diperoleh dari studi literatur (jurnal, buku, internet dan kepustakaan lainnya) terkait dengan halhal yang dibahas dalam penelitian ini untuk digunakan dalam membantu menjawab pertanyaan penelitian dan hipotesis, serta untuk memahami data primer secara lebih mendalam.

Populasi dalam penelitian ini adalah wakif gen Y di Indonesia dengan rentang kelahiran tahun 19802000. Jumlah sampel yang diteliti adalah sebanyak 160 sampel yang telah masuk dalam skrining awal. Hal ini sesuai dengan jumlah minimum sampel yang dibutuhkan untuk analisa structural equation modeling (SEM). Bentler dan Chou (1987) dalam Zuhdi et al. (2016) merekomendasikan jumlah sampel yang harus dipenuhi untuk estimasi SEM ialah 5 kali parameter yang akan diestimasi dimana jumlah parameter dalam penelitian ini ada sebanyak 31 buah sehingga minimal jumlah sampel sebanyak 155 responden. Teknik pengambilan sampel yang digunakan dalam penelitian ini adalah nonprobability samping. Jenis pengambilan sampel dalam teknik nonprobability samping yang dipilih adalah samping purposive dengan kategori responden adalah (1) lahir pada rentang tahun 19802000, (2) seorang Muslim/Muslimah, (3) pernah menyisihkan pendapatan/penerimaan untuk program wakaf uang/melalui uang, (4) pernah melakukan transaksi pembayaran digital (online) melalui telepon seluler (Mis: transfer via Mobile Banking/SMS banking/ Internet Banking/QR/GoPay/OVO/LinkAja, dll).

Penulis melakukan pengumpulan data primer melalui penyebaran kuesioner online dengan membuat daftar pertanyaan tertutup untuk dapat memperoleh gambaran karakteristik wakif gen Y. Penulis juga membuat daftar pernyataan tertutup yang menggunakan skala likert untuk menganalisis faktor-faktor apa saja yang memengaruhi intensi muslim gen $\mathrm{Y}$ dalam pemanfaatan teknologi digital payment untuk mendorong gerakan berwakaf uang/melalui uang secara digital di Indonesia dengan nilai pembobotan sebagai berikut: 1) sangat setuju (SS) dengan bobot 5; 2) setuju (S) dengan bobot 4; 3) cukup setuju (CS) dengan bobot 3; 4) tidak setuju (TS) dengan bobot 2; dan 5) sangat tidak setuju (STS) dengan bobot 1 . Teknik analisis data yang dilakukan dalam penelitian ini dijelaskan dalam Tabel 1.

Secara umum dalam penelitian ini terdapat dua jenis analisis yang dilakukan, yaitu analisis deskriptif dan Struktural Equation Modeling (SEM). Analisis deskriptif yang diuraikan tentang karakteristik dari wakif gen Y dalam gerakan berwakaf digital. Model struktural menggambarkan pengaruh-pengaruh antara variabel laten. Sepryna dan Nissa (2013) menjelaskan bahwa model pengukuran harus terlebih dahulu diuji validitas dan reliabilitasnya. Uji validitas dari model pengukuran dapat diperiksa dengan melihat nilai t-value $\geq 1,96$ dan standardized loading factor (SLF) $\geq 0,50$ dari variabel-variabel teramati dalam model. Namun menurut Igbaria et al. (1997) nilainya masih bisa dipertimbangkan (indikator tidak dihapus) dengan batas SLF $\geq 0,30$ sesuai kebijakan peneliti (Wijanto 2008). Uji reliabilitas dari model pengukuran dilakukan dengan menghitung nilai construct reliability (CR) dan variance extracted (VE). Menurut Hair (1998) dalam Sepryna dan Nissa (2013), sebuah konstruk dapat dianggap memiliki reliabilitas yang baik bila nilai CRnya $\geq 0,70$ dan VE-nya $\geq 0,50$. Sedangkan model struktural dilakukan melalui uji kecocokan model struktural (goodnes of fit). Uji kecocokan ini dilakukan untuk seluruh variabel dalam model.

Penelitian ini dilakukan kepada wakif gen $\mathrm{Y}$ yang merupakan potensi demografi wakif masa kini untuk dapat dioptimalkan dalam meningkatkan penghimpunan dana wakaf uang atau melalui uang dengan adanya kemajuan teknologi pembayaran digital (digital payment). Dalam hal ini dilakukan analisis SEM untuk mengetahui variabel yang berpengaruh terhadap intensi perilaku wakif gen $\mathrm{Y}$ dalam mendorong penggunaan teknologi digital payment untuk gerakan berwakaf digital dengan mengacu pada ketujuh variabel yaitu performance expectancy/harapan kinerja, effort expectancy/harapan usaha, social influence/pengaruh sosial, facilitating condition/kondisi fasilitasi, hedonic motivation/motivasi hedonisme, price value/nilai harga, dan habit/kebiasaan) dalam model UTAUT 2 yang dikembangkan oleh Venkatesh et al. (2012) serta penambahan satu variabel yaitu perceived security/ keamanan dirasakan yang dikembangkan dalam model Factors Influencing Consumer's Intention to Use e-Payment System oleh Junadi dan Sfenrianto (2015). Gambar 1 memperlihatkan model intensi terhadap perilaku penggunaan teknologi digital payment untuk mendorong gerakan berwakaf digital pada wakif gen $\mathrm{Y}$ yang dikembangkan oleh peneliti. Berdasarkan Gambar 1 dapat dijelaskan bahwa :

1. H1 : Terdapat pengaruh antara variabel performance expectancy (PE) dengan intensi pada perilaku penggunaan teknologi digital payment untuk berwakaf uang/melalui uang

2. H2 : Terdapat pengaruh antara variabel effort 
expectancy (EE) dengan intensi pada perilaku penggunaan teknologi digital payment untuk berwakaf uang/melalui uang

3. H3 : Terdapat pengaruh antara variabel social influence (SI) dengan intensi pada perilaku penggunaan teknologi digital payment untuk berwakaf uang/melalui uang

4. H4 : Terdapat pengaruh antara variabel facilitating condition (FC) dengan intensi pada perilaku penggunaan teknologi digital payment untuk berwakaf uang/melalui uang
5. H5 : Terdapat pengaruh antara variabel hedonic motivation (HM) dengan intensi pada perilaku penggunaan teknologi digital payment untuk berwakaf uang/melalui uang

6. H6 : Terdapat pengaruh antara variabel price value (PV) dengan intensi pada perilaku penggunaan teknologi digital payment untuk berwakaf uang/ melalui uang

7. H7 : Terdapat pengaruh antara variabel habit $(\mathrm{HT})$ dengan intensi pada perilaku penggunaan teknologi digital payment untuk berwakaf uang/melalui uang

Tabel 1. Teknik analisis data

\begin{tabular}{|c|c|c|}
\hline Tujuan & Metode Analisis & Output \\
\hline $\begin{array}{l}\text { Mendeskripsikan karakteristik wakif } \\
\text { gen Y terkait terhadap gerakan } \\
\text { berwakaf digital }\end{array}$ & Analisis Deskriptif & $\begin{array}{l}\text { Gambaran tentang karakteristik dari } \\
\text { muslim gen Y dalam gerakan berwakaf } \\
\text { digital }\end{array}$ \\
\hline $\begin{array}{l}\text { Menganalisis faktor-faktor apa saja } \\
\text { yang memengaruhi intensi wakif gen Y } \\
\text { dalam menggunakan teknologi digital } \\
\text { payment untuk mendorong gerakan } \\
\text { berwakaf digital }\end{array}$ & $\begin{array}{l}\text { Analisis Structural Equation Modeling } \\
\text { (SEM) dengan pendekatan variabel } \\
\text { pada model UTAUT } 2 \text { oleh Venkatesh } \\
\text { et al. (2012) serta Junadi dan } \\
\text { Sfenrianto (2015) } \\
\end{array}$ & $\begin{array}{l}\text { Faktor-faktor yang berpengaruh } \\
\text { terhadap intensi perilaku muslim gen Y } \\
\text { dalam menggunakan teknologi digital } \\
\text { payment untuk mendorong gerakan } \\
\text { berwakaf digital }\end{array}$ \\
\hline
\end{tabular}

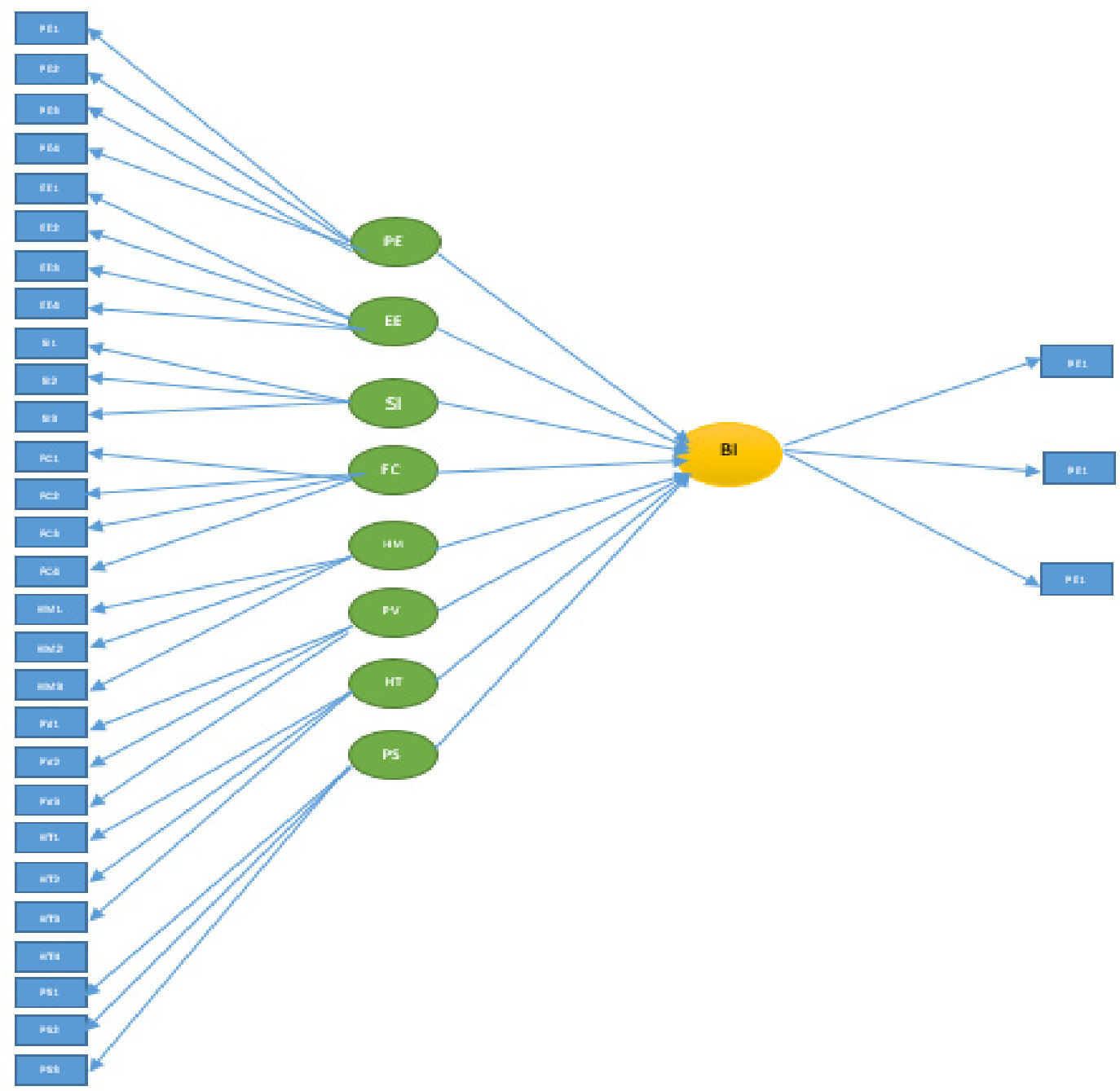

Gambar 1. Model intensi terhadap perilaku penggunaan teknologi digital payment (Venkatesh et al. 2012; Junadi dan Sfenrianto, 2015) 
8. H8 : Terdapat pengaruh antara variabel perceived security (PS) dengan intensi pada perilaku penggunaan teknologi digital payment untuk berwakaf uang/melalui uang

Tabel 2 memperlihatkan ukuran berdasarkan faktor model intensi terhadap perilaku penggunaan teknologi digital payment. Faktor tersebut meliputi performance expectancy, effort expectancy, social influence, facilitating condition, hedonic motivation, price value, habit, perceived security dan behavioral intention. Ukuran faktor-faktor pada model intensi ini dikembangkan dari ukuran faktor-faktor yang ada dalam penelitian Venkatesh et al. (2012) serta Junadi dan Sfenrianto (2015).

Tabel 2. Ukuran berdasarkan faktor model intensi terhadap perilaku penggunaan teknologi digital payment

\begin{tabular}{|c|c|c|}
\hline Variabel & Faktor & Ukuran \\
\hline \multirow[t]{4}{*}{ Eksogen } & \multirow{4}{*}{$\begin{array}{l}\text { Performance } \\
\text { Expectancy } \\
\text { (Harapan } \\
\text { Kinerja) }\end{array}$} & $\begin{array}{l}\text { PE1 : Penggunaan teknologi pembayaran digital untuk berwakaf uang/melalui uang secara } \\
\text { digital akan berguna dalam kehidupan sehari-hari }\end{array}$ \\
\hline & & $\begin{array}{l}\text { PE2 : Penggunaan teknologi pembayaran digital untuk berwakaf uang/melalui uang secara } \\
\text { digital akan meningkatkan peluang saya untuk mencapai hal yang penting }\end{array}$ \\
\hline & & $\begin{array}{l}\text { PE3 : Penggunaan teknologi pembayaran digital untuk berwakaf uang/melalui uang secara } \\
\text { digital akan membantu saya menyelesaikan banyak hal lebih cepat }\end{array}$ \\
\hline & & $\begin{array}{l}\text { PE4 : Penggunaan teknologi pembayaran digital untuk berwakaf uang/melalui uang secara } \\
\text { digital akan meningkatkan produktivitas saya }\end{array}$ \\
\hline \multirow[t]{4}{*}{ Eksogen } & \multirow{4}{*}{$\begin{array}{l}\text { Effort } \\
\text { Expectancy } \\
\text { (Harapan } \\
\text { Usaha) }\end{array}$} & $\begin{array}{l}\text { EE1: Saya akan mudah mempelajari cara penggunaan teknologi pembayaran digital untuk } \\
\text { berwakaf uang/melalui uang secara digital }\end{array}$ \\
\hline & & $\begin{array}{l}\text { EE2: Saya akan mudah mengerti dalam berinteraksi dengan teknologi pembayaran digital } \\
\text { untuk berwakaf uang/melalui uang secara digital }\end{array}$ \\
\hline & & $\begin{array}{l}\text { EE3: Saya akan mudah menggunakan teknologi pembayaran digital untuk berwakaf uang/ } \\
\text { melalui uang secara digital }\end{array}$ \\
\hline & & $\begin{array}{l}\text { EE4: Saya akan mudah menjadi ahli dalam menggunakan teknologi pembayaran digital untuk } \\
\text { berwakaf uang/melalui uang secara digital }\end{array}$ \\
\hline \multirow[t]{3}{*}{ Eksogen } & \multirow{3}{*}{$\begin{array}{l}\text { Social } \\
\text { Influence } \\
\text { (Pengaruh } \\
\text { Sosial) }\end{array}$} & $\begin{array}{l}\text { SI1 : Orang-orang yang penting bagi saya, berpikir bahwa saya harus menggunakan teknologi } \\
\text { pembayaran digital untuk berwakaf uang/melalui uang secara digital }\end{array}$ \\
\hline & & $\begin{array}{l}\text { SI2 : Orang-orang yang memengaruhi perilaku saya, berpikir bahwa saya harus menggunakan } \\
\text { teknologi pembayaran digital untuk berwakaf uang/melalui uang secara digital }\end{array}$ \\
\hline & & $\begin{array}{l}\text { SI3 : Orang-orang yang pendapatnya saya hargai, lebih suka saya menggunakan teknologi } \\
\text { pembayaran digital untuk berwakaf uang/melalui uang secara digital }\end{array}$ \\
\hline \multirow[t]{4}{*}{ Eksogen } & \multirow{4}{*}{$\begin{array}{l}\text { Facilitating } \\
\text { Condition } \\
\text { (Kondisi } \\
\text { Fasilitasi) }\end{array}$} & $\begin{array}{l}\text { FC1 : Saya memiliki sumber daya yang diperlukan dalam menggunakan teknologi } \\
\text { pembayaran digital untuk berwakaf uang/melalui uang secara digital }\end{array}$ \\
\hline & & $\begin{array}{l}\text { FC2 : Saya memiliki pengetahuan yang diperlukan dalam menggunakan teknologi } \\
\text { pembayaran digital untuk berwakaf uang/melalui uang secara digital }\end{array}$ \\
\hline & & $\begin{array}{l}\text { FC3 : Perangkat ponsel yang saya gunakan kompatibel dengan teknologi pembayaran digital } \\
\text { untuk berwakaf uang/melalui uang secara digital }\end{array}$ \\
\hline & & $\begin{array}{l}\text { FC4 : Saya bisa mendapatkan bantuan dari orang lain ketika saya mengalami kesulitan } \\
\text { menggunakan teknologi pembayaran digital untuk berwakaf uang/melalui uang secara digital }\end{array}$ \\
\hline \multirow[t]{3}{*}{ Eksogen } & \multirow{3}{*}{$\begin{array}{l}\text { Hedonic } \\
\text { Motivation } \\
\text { (Motivasi } \\
\text { Hedonis) }\end{array}$} & $\begin{array}{l}\text { HM1 : Penggunaan teknologi pembayaran digital untuk berwakaf uang/melalui uang secara } \\
\text { digital itu akan menyenangkan }\end{array}$ \\
\hline & & $\begin{array}{l}\text { HM2 : Penggunaan teknologi pembayaran digital untuk berwakaf uang/melalui uang secara } \\
\text { digital itu akan memberikan kenyamanan }\end{array}$ \\
\hline & & $\begin{array}{l}\text { HM3 : Penggunaan teknologi pembayaran digital untuk berwakaf uang/melalui uang secara } \\
\text { digital itu akan sangat menghibur }\end{array}$ \\
\hline \multirow[t]{3}{*}{ Eksogen } & \multirow[t]{3}{*}{$\begin{array}{l}\text { Price Value } \\
\text { (Nilai Harga) }\end{array}$} & $\begin{array}{l}\text { PV1 : Teknologi pembayaran digital untuk berwakaf uang/melalui uang secara digital itu } \\
\text { biayanya dapat terjangkau }\end{array}$ \\
\hline & & $\begin{array}{l}\text { PV2 : Teknologi pembayaran digital untuk berwakaf uang/melalui uang secara digital } \\
\text { sebanding dengan nilai manfaat dan biayanya }\end{array}$ \\
\hline & & $\begin{array}{l}\text { PV3 : Pada biaya yang berlaku saat ini, teknologi pembayaran digital untuk berwakaf uang/ } \\
\text { melalui uang secara digital dapat memberikan manfaat yang baik }\end{array}$ \\
\hline
\end{tabular}


Tabel 2. Ukuran berdasarkan faktor model intensi terhadap perilaku penggunaan teknologi digital payment (Lanjutan)

\begin{tabular}{lll}
\hline Variabel & Faktor & Ukuran \\
\hline Eksogen & Habit & HT1 : Penggunaan teknologi pembayaran digital untuk berwakaf uang/melalui uang secara \\
& (Kebiasaan) & digital dapat menjadi kebiasaan saya \\
& & HT2 : Saya dapat memiliki ketergantungan yang tinggi dalam menggunakan teknologi \\
& pembayaran digital untuk berwakaf uang/melalui uang secara digital \\
& & HT3 : Saya harus menggunakan teknologi pembayaran digital untuk berwakaf uang/melalui \\
& uang secara digital
\end{tabular}

\section{HASIL}

\section{Profil Responden}

Profil responden pada penelitian ini meliputi beberapa faktor demografi, yaitu jenis kelamin, usia, status pernikahan, domisili, jenis pekerjaan, lokasi bekerja, dan besarnya pendapatan per bulan sebagaimana disajikan pada Tabel 3. Berdasarkan profil responden dapat disampaikan bahwa dominansi wakif gen $\mathrm{Y}$ yang menggunakan teknologi digital payment untuk pembayaran wakaf sudah mengarah pada budaya digital marketing 4,0 yang disampaikan oleh Kotler et al. (2017) dalam buku marketing 4,0, yaitu kaum muda, perempuan, dan warganet. Responden sebagian besar merupakan pekerja dengan tingkat pendidikan dan pendapatan yang tinggi. Oleh karena itu, lembaga nazhir dapat meningkatkan kekuatan branding serta promosi layanan wakaf digital untuk peningkatan penghimpunan dana wakaf perorangan khususnya melalui pendekatan wakif gen Y perempuan.

\section{Karakteristik Responden}

Karakteristik dari responden wakif gen $\mathrm{Y}$ terhadap sudut pandang pembayaran digital wakaf uang atau wakaf melalui uang dijelaskan sebagai berikut:
Pengetahuan Wakaf

Berdasarkan data penelitian, seluruh responden menjawab $100 \%$ bahwa wakaf sebagai pahala yang terus mengalir. Hal ini dapat dilihat sebagai kesadaran responden dalam melakukan kebaikan menuju akhirat. Sehingga peluang peningkatan dana wakaf uang atau wakaf melalui uang melalui wakif gen $\mathrm{Y}$ dapat dioptimalkan potensinya dengan adanya teknologi pembayaran digital untuk berwakaf.

\section{Informasi Ajakan Wakaf Uang/Melalui Uang}

Berdasarkan data penelitian, mayoritas responden mendapatkan informasi ajakan wakaf yang berasal dari lembaga nazhir $(69,4 \%)$. Selanjutnya diikuti dengan yayasan sosial/keagamaan/kemanusiaan $\quad(35,0 \%)$, lembaga perbankan $(33,8 \%)$, guru/pemuka agama (32,5\%), teman $(29,0 \%)$, keluarga $(26,3 \%)$, dan lembaga crowdfunding $(23,1 \%)$. Hal ini menunjukkan bahwa perlu adanya kolaborasi bersama yang dilakukan oleh lembaga nazhir dengan melibatkan peranan yayasan sosial/keagamaan/kemanusiaan, lembaga perbankan, guru/pemuka agama, serta lembaga crowdfunding dalam mensosialisasikan informasi ajakan berwakaf 
uang/melalui uang secara aktif. Sehingga dengan adanya jejaring informasi yang semakin luas diharapkan dapat meningkatkan literasi gen $\mathrm{Y}$ tentang informasi wakaf uang/melalui uang yang juga dapat disampaikan kembali kepada teman maupun keluarganya.

Sumber Media Informasi Ajakan Wakaf Uang/Melalui Uang

Berdasarkan data penelitian, mayoritas responden mendapati sumber media informasi ajakan wakaf uang/melalui uang melalui instagram $(73,8 \%)$, diikuti whatsapp $(53,1 \%)$, website $(44,4 \%)$, brosur $(24,4 \%)$, email $(20,6 \%)$ dan sisanya adalah melalui sosial media seperti facebook dan twitter, telegram, televisi, dan radio $(32,6 \%)$. Hal ini mengidentifikasikan bahwa instagram dan whatsapp menjadi sumber media yang dominan dilihat dalam perolehan informasi responden. Sehingga lembaga wakaf dapat memanfaatkan media sosial instagram dan whatsapp sebagai media utama untuk menyebarkan informasi terkait sosialisasi, edukasi, dan promosi layanan digital wakaf uang/ melalui uang. Selain itu, peningkatan sosialisasi melalui website juga dapat menjadi hal yang perlu diperhatikan oleh lembaga wakaf sebagai media resmi yang dimiliki

Tabel 3. Profil responden

\begin{tabular}{llcc}
\hline Demografi & Kategori & $\begin{array}{c}\text { Frekuensi } \\
\text { (Orang) }\end{array}$ & $(\%)$ \\
\hline Jenis & Laki-Laki & 46 & 28,8 \\
Kelamin & Perempuan & 114 & 71,3 \\
Usia & $18-24$ & 21 & 13,1 \\
& $25-34$ & 118 & 73,8 \\
& 35-40 & 21 & 13,1 \\
Status & Single & 71 & 44,4 \\
Pernikahan & Menikah & 89 & 55,6 \\
Pendidikan & SMA/SMK/MA & 12 & 7,5 \\
& Diploma & 9 & 5,6 \\
& D4/Sarjana & 103 & 64,4 \\
& Pascasarjana & 36 & 22,5 \\
Domisili & Jadebotabek & 131 & 81,9 \\
Tempat & Luar Jadebotabek & 29 & 18,1 \\
\hline
\end{tabular}

untuk penyebaran informasi terkait sosialisasi, edukasi, dan promosi layanan digital wakaf uang/melalui uang.

Tingkat Kepentingan Informasi Ajakan Layanan Penyaluran Pembayaran Wakaf Uang/Melalui Uang

Berdasarkan data penelitian, mayoritas responden menyampaikan bahwa informasi ajakan layanan penyaluran pembayaran wakaf uang/melalui uang sangat penting untuk diperoleh $(56,9 \%)$. Adapun responden lainnya menyatakan penting $(36,3 \%)$, cukup penting $(5,6 \%)$, tidak penting $(0,6 \%)$, dan sangat tidak penting $(0,6 \%)$. Hal ini mengidentifikasikan bahwa responden tetap membutuhkan informasi ajakan layanan penyaluran pembayaran wakaf uang/melalui uang. Diharapkan dengan adanya informasi ajakan tersebut, responden dapat turut berkontribusi atas pelaksanaan program-program yang disampaikan oleh lembaga pengelola wakaf. Hal ini juga mengidentifikasikan bahwa responden tetap membutuhkan informasi ajakan layanan penyaluran pembayaran wakaf uang/melalui uang. Sehingga diharapkan dengan adanya informasi ajakan tersebut, responden dapat turut berkontribusi atas pelaksanaan program-program yang disampaikan oleh lembaga pengelola wakaf.

\begin{tabular}{llcc}
\hline Demografi & Kategori & $\begin{array}{c}\text { Frekuensi } \\
\text { (Orang) }\end{array}$ & (\%) \\
\hline Pekerjaan & Pelajar/Mahasiswa & 6 & 3,8 \\
& PNS & 14 & 8,8 \\
& Pegawai BUMN & 8 & 5,0 \\
& Pegawai Swasta & 101 & 63,1 \\
& Wiraswasta & 18 & 11,3 \\
& Ibu Rumah Tangga & 13 & 8,1 \\
Lokasi & Jadebotabek & 129 & 80,6 \\
Bekerja & Luar Jadebotabek & 31 & 19,4 \\
Pendapatan & Rp1 Juta-<5.240.000 & 67 & 41,9 \\
per bulan & Rp5.240.000-10 Juta & 58 & 36,3 \\
& $>$ Rp10 Juta-15 Juta & 20 & 12,5 \\
& $>$ Rp15 Juta & 15 & 9,4 \\
\hline
\end{tabular}


Tingkat Ketertarikan Mengikuti Program Wakaf Uang/ Melalui Uang

Berdasarkan data penelitian, mayoritas responden menyampaikan ketertarikan yang sangat tinggi dalam mengikuti program wakaf uang/melalui uang (52,5\%), menarik $(39,4 \%)$, cukup menarik $(7,5 \%)$, tidak menarik $(0,6 \%)$ dan sangat tidak menarik $(0 \%)$. Hal ini mengidentifikasikan bahwa responden wakif gen $\mathrm{Y}$ memiliki kedermawanan yang tinggi dankecenderungan untuk berbagi kebaikan bagi kemaslahatan banyak orang.

Pertimbangan Ketertarikan Mengikuti Layanan Program Wakaf Uang/Melalui Uang

Berdasarkan data penelitian, adanya ragam kemudahan fasilitas penyaluran pembayaran wakaf uang/ melalui uang $(63,7 \%)$ menjadi faktor utama dalam pertimbangan responden mengikuti program wakaf uang/melalui uang. Selanjutnya, diikuti dengan adanya perangkat hukum wakaf uang/melalui uang yang jelas secara syariat Islam sebesar (50\%), program penghimpunan dengan nilai nominal wakaf uang/ melalui uang yang terjangkau $(43,8 \%)$, adanya program yang menarik untuk tujuan produktif atau investasi baik di sektor ril maupun sektor keuangan $(41,9 \%)$, dan yang terakhir adanya sosialisasi yang menarik atas layanan program wakaf uang/melalui uang (36,3\%). Hal ini mengidentifikasikan bahwa faktor kemudahan menjadi pertimbangan utama responden, baik terhadap penggunaannya maupun terhadap tujuannya agar dapat berbagi dengan mudah kapanpun dan dimanapun.

Pertimbangan Pemilihan Lembaga Pengelola Wakaf Uang/Melalui Uang

Berdasarkan data penelitian, mayoritas responden memilih legalitas lembaga dalam pertimbangan pemilihan lembaga pengelola wakaf uang/melalui uang $(71,3 \%)$, lalu diikuti dengan program manfaat wakaf uang/melalui uang $(66,9 \%)$, pelaporan wakaf uang/ melalui uang secara terbuka $(54,4 \%)$, ragam fasilitas penyaluran pembayaran $(47,5 \%)$, popularitas lembaga $(30,0 \%)$, dan yang terakhir adalah Layanan lembaga $(28,7 \%)$.
Intensi Berwakaf Uang/Melalui Uang dalam periode Januari - Agustus 2020

Berdasarkan data penelitian, mayoritas responden hanya pernah satu kali dalam periode Januari 2020-Agustus 2020 (25,8\%), 2-3 kali dalam periode Januari 2020 Agustus 2020 (20.1\%), belum melakukan kembali wakaf uang/melalui uang dalam periode Januari 2020-Agustus $2020(19,5 \%)>3$ kali dalam periode Januari 2020-Agustus 2020 (16,4\%), setiap bulan minimal 1 kali $(15,7 \%)$, dan hanya sedikit responden yang melakukan wakaf uang/melalui uang setiap bulan $>1$ kali $(2,5 \%)$. Hal ini mengidentifikasikan bahwa program gerakan berwakaf dan penyebaran informasi terkait sosialisasi, edukasi, dan promosi layanan digital wakaf uang/melalui uang perlu dioptimalkan oleh lembaga pengelola wakaf.

Metode Pembayaran untuk Pembayaran Wakaf Uang/ Melalui Uang

Berdasarkan data penelitian, mayoritas responden menggunakan metode transfer via mobile banking $(87,5 \%)$ untuk pembayaran wakaf uang/melalui uang secara digital. Selanjutnya metode lain yang digunakan adalah transfer via e-wallet $(18,8 \%)$, setoran tunai $(10 \%)$, transfer via internet banking $8,1 \%)$, transfer via QR (2,5\%), pemindahbukuan terjadwal (autodebet) $(2,5 \%)$ dan transfer via SMS banking (0\%). Hal ini mengidentifikasikan bahwa penggunaan mobile banking dan $e$-wallet menjadi pilihan yang banyak digunakan oleh responden dalam penyaluran pembayaran wakaf uang/melalui uang.

Pengetahuan Adanya Layanan Digital Wakaf Uang/ Melalui Uang

Berdasarkan data penelitian, $95 \%$ responden mengetahui bahwa adanya layanan digital wakaf uang/melalui uang yang disediakan oleh Lembaga Pengelola Wakaf, sedangkan 5\% responden tidak mengetahui adanya layanan digital wakaf uang/melalui uang tersebut. Hal ini mengidentifikasikan bahwa tidak semua responden mengetahui adanya layanan digital wakaf uang/melalui uang dan diperlukan peningkatan sosialisasi, edukasi dan promosi atas layanan digital tersebut. 
Tingkat Ketertarikan Mengikuti Program Wakaf Uang/ Melalui Uang Secara Digital

Berdasarkan data penelitian, mayoritas responden menyampaikan ketertarikan yang sangat tinggi dalam mengikuti program wakaf uang/melalui uang secara digital $(60,6 \%)$, menarik $(34,4 \%)$, cukup menarik $(3,8 \%)$, tidak menarik $(0,6 \%)$ dan sangat tidak menarik $(0,6 \%)$. Hal ini sesuai dengan gambaran dari karakteristik gen $\mathrm{Y}$ yang cenderung memanfaatkan penggunaan teknologi digital payment sebagai layanan transaksi non-tunai.

Tingkat Kepentingan Metode Pembayaran Digital untuk Pembayaran Wakaf Uang/Melalui Uang

Berdasarkan data penelitian, mayoritas responden menyampaikan bahwa metode pembayaran digital untuk pembayaran wakaf uang/melalui uang adalah sangat penting $(73,8 \%)$. Adapun responden lainnya menyatakan penting $(22,5 \%)$, cukup penting $(3,1 \%)$, dan sangat tidak penting $(0 \%)$. Hal ini mengidentifikasikan bahwa mayoritas responden menyetujui adanya metode pembayaran digital untuk pembayaran wakaf uang/ melaluiuang akan sangat bermanfaat dalam memberikan kemudahan untuk menyampaikan pembayaran wakaf uang/melalui uang ke sasaran yang ingin dituju.

Pertimbangan Ketertarikan Berwakaf Uang/Melalui Uang Secara Digital

Berdasarkan data penelitian, mayoritas responden memilih kemudahan dalam penggunaan metode pembayaran digital secara online menjadi faktor utama dalam ketertarikan berwakaf uang/melalui uang secara digital (72,5\%), kemudahan untuk berwakaf kapanpun dan dimanapun (69,4\%), ketersediaan ragam pilihan metode pembayaran digital secara online $(61,9 \%)$, ketersediaan ponsel dengan perangkat teknologi yang mendukung (46,3\%), ketersediaan ragam pilihan mitra layanan digital lembaga pengelola wakaf $(38,1 \%)$, penetapan hukum dan syariat Islam yang membolehkan penggunaan pembayaran digital untuk berwakaf uang/ melaluiuang $(37,5 \%)$, kecenderungan transaksi cashless secara non tunai $(36,3 \%)$, keterbatasan untuk datang langsung ke lembaga pengelola wakaf $(31,9 \%)$, dan sedikit pertimbangan tentang kecepatan penghimpunan dana dalam mencapai sasaran program wakaf uang/ melalui uang $(24,4 \%)$. Hal ini mengidentifikasikan bahwa faktor kemudahan adalah menjadi pertimbangan utama responden, baik terhadap penggunaannya maupun terhadap tujuannya agar dapat berbagi dengan mudah kapanpun dan dimanapun.

Rekomendasi Layanan Program Wakaf Uang/Melalui Uang Secara Digital

Berdasarkan data penelitian, mayoritas responden sangat merekomendasikan layanan program wakaf uang/melalui uang secara digital (66,9\%), 28,1\% merekomendasikan, 3,8\% cukup merekomendasikan, sedangkan $1,3 \%$ responden tidak merekomendasikan. Sehingga secara umum responden wakif gen $\mathrm{Y}$ akan memberikan rekomendasinya kepada yang lain untuk dapat menggunakan layanan pembayaran digital untuk berwakaf uang/melalui uang.

\section{Analisis Structural Equation Modeling (SEM)}

Pengukuran intensi terhadap perilaku wakif gen $\mathrm{Y}$ dalam mendorong gerakan berwakaf uang atau wakaf melalui uang secara digital dilakukan dengan pengujian terhadap variabel yang dianggap berpengaruh terhadap perilaku penggunaan teknologi digital payment. Dalam hal ini, dilakukan analisis structural equation modeling (SEM) untuk mengetahui hubungan-hubungan antarvariabel tersebut dengan menggunakan piranti lunak Lisrel.

Langkah pertama adalah analisis model pengukuran. Uji kecocokan model pengukuran dalam SEM menggunakan uji validitas dan reliabilitas. Hasil uji validitas per dimensi pada peubah masing-masing faktor diuraikan secara rinci dengan menggunakan kriteria standardized loading factor (SLF). Yoepitasari dan Khasanah (2018) menjelaskan bahwa untuk mendapatkan kemaknaan dari dimensi-dimensi yang terekstraksi dalam membentuk variabel laten, dapat diperoleh dari nilai standardized loading factor dari masing masing dimensi. Jika diperoleh adanya nilai standardized loading factor yang lebih besar dari 0.50; maka hal tersebut mengindikasikan bahwa dimensi tersebut cukup baik untuk terekstraksi membentuk variabel laten. Sedangkan untuk menguji reliabilitas menurut Hair et al. (2014), dapat menggunakan construct reliability (CR) dan variance extracted (VE). Suatu pengukuran dikatakan mempunyai reliabilitas tinggi apabila nilai $\mathrm{CR} \geq 0,7$ dan $\mathrm{VE} \geq 0,5$. Berdasarkan piranti lunak Lisrel, hasil pengujian konstruk validitas dan reliabilitas untuk masing-masing pengaruh faktor 
terhadap variabel laten diuraikan pada Tabel 4 dan Tabel 5. Berdasarkan pada hasil model struktural untuk menjawab hipotesa penelitian, maka dapat disampaikan keluaran model struktural terdiri atas standardized

Tabel 4. Hasil pengujian model pengukuran

\begin{tabular}{lcccc}
\hline Indikator & T hitung & SLF & CR & VE \\
\hline PE 1 & 16,85 & 0,84 & 0,94 & 0,80 \\
PE 2 & 18,02 & 0,89 & & \\
PE 3 & 17,82 & 0,89 & & \\
PE 4 & 19,22 & 0,95 & & \\
EE 1 & 17,95 & 0,90 & 0,93 & 0,77 \\
EE 2 & 16,05 & 0,89 & & \\
EE 3 & 14,74 & 0,83 & & \\
EE 4 & 18,17 & 0,90 & & \\
SI 1 & 16,96 & 0,89 & 0,91 & 0,76 \\
SI 2 & 16,35 & 0,89 & & \\
SI 3 & 15,78 & 0,84 & & \\
FC 1 & 15,59 & 0,84 & 0,91 & 0,73 \\
FC 2 & 15,42 & 0,84 & & \\
FC 3 & 15,79 & 0,89 & & \\
FC 4 & 16,60 & 0,85 & & \\
\hline
\end{tabular}

loading factor dan thitung. Gambar 2 memperlihatkan standardized loading factor. Gambar 3 memperlihatkan $\mathrm{T}$ hitung model struktural.

\begin{tabular}{lcccc}
\hline Indikator & T hitung & SLF & CR & VE \\
\hline HM 1 & 16,82 & 0,89 & 0,91 & 0,76 \\
HM 2 & 17,18 & 0,89 & & \\
HM 3 & 16,78 & 0,85 & & \\
PV 1 & 17,75 & 0,94 & 0,92 & 0,80 \\
PV 2 & 18,20 & 0,90 & & \\
PV 3 & 16,46 & 0,84 & & \\
HT 1 & 20,00 & 0,95 & 0,93 & 0,77 \\
HT 2 & 18,42 & 0,89 & & \\
HT 3 & 18,84 & 0,85 & & \\
HT 4 & 16,62 & 0,83 & & \\
PS 1 & 17,16 & 0,89 & 0,89 & 0,73 \\
PS 2 & 17,15 & 0,84 & & \\
PS 3 & 15,96 & 0,84 & & \\
BI 1 & 7,22 & 0,95 & 0,93 & 0,83 \\
BI 2 & 30,97 & 0,89 & & \\
BI 3 & 31,08 & 0,89 & & \\
\hline
\end{tabular}

Keterangan: *)SLF (Standardized Loading Factor, nilai SLF yang baik $\geq 0.50$ ); **)THitung (Nilai t-hitung $\geq \mathrm{t}$-tabel 1.96 artinya pengaruh signifikan); ***)CR (Construct Reliability, nilai CR yang baik $\geq 0.70) ; * * * *) \mathrm{VE}($ Variance Extracted, nilai VE yang baik $\geq 0.50)$

Tabel 5. Hasil uji kecocokan keseluruhan model

\begin{tabular}{lccc}
\hline Ukuran kecocokan keseluruhan model & Hasil perhitungan & Syarat & Keterangan \\
\hline $\begin{array}{l}\text { Absolute fit Model } \\
\text { Root Mean Square Error of Approximation (RMSEA) }\end{array}$ & 0,00 & $\leq 0,08$ & Good Fit \\
Goodness of Fit Index (GFI) & 1,00 & $\geq 0,90$ & Good Fit \\
Incremental Fit Model & & & \\
Comparative Fit Index (CFI) & 1,00 & $\geq 0,90$ & Good Fit \\
Normed Fit Index (NFI) & 1,00 & $\geq 0,90$ & Good Fit \\
Non-Normed Fit Index (NNFI) & 1,00 & $\geq 0,90$ & Good Fit \\
Incremental Fit Index (IFI) & 1,00 & $\geq 0,90$ & Good Fit \\
Relative Fit Index (RFI) & 0,99 & $\geq 0,90$ & Good Fit \\
Parsimonious Fit Model & & & \\
Adjusted Goodness of Fit Index (AGFI) & 0,99 & Good Fit \\
Parsimony Goodness of Fit Index (PGFI) & 0,80 & Semakin tinggi & \\
& & semakin baik (0-1) & \\
\hline
\end{tabular}




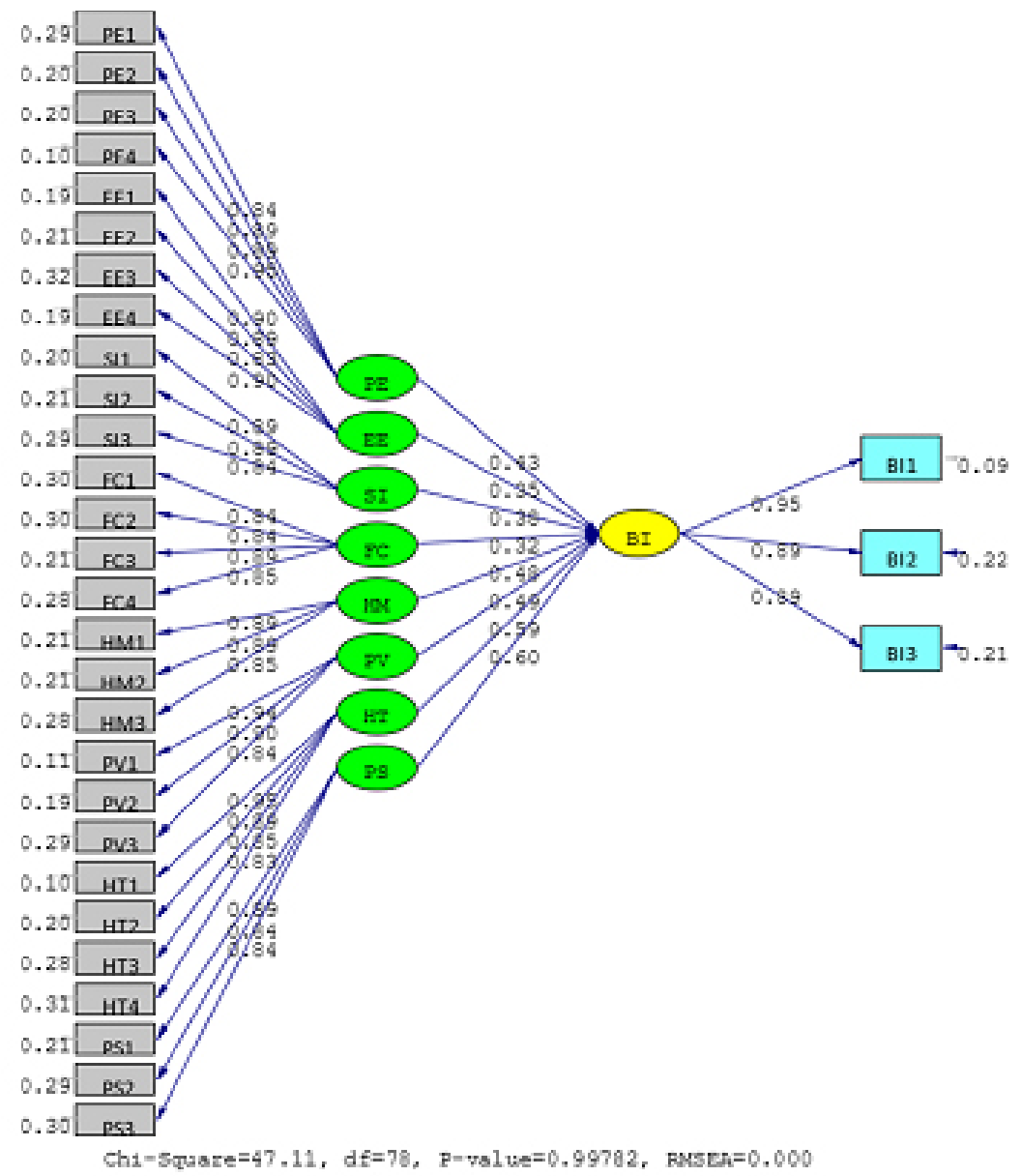

Gambar 2. Standardized Loading Factor (SLF) model intensi terhadap perilaku penggunaan teknologi digital payment

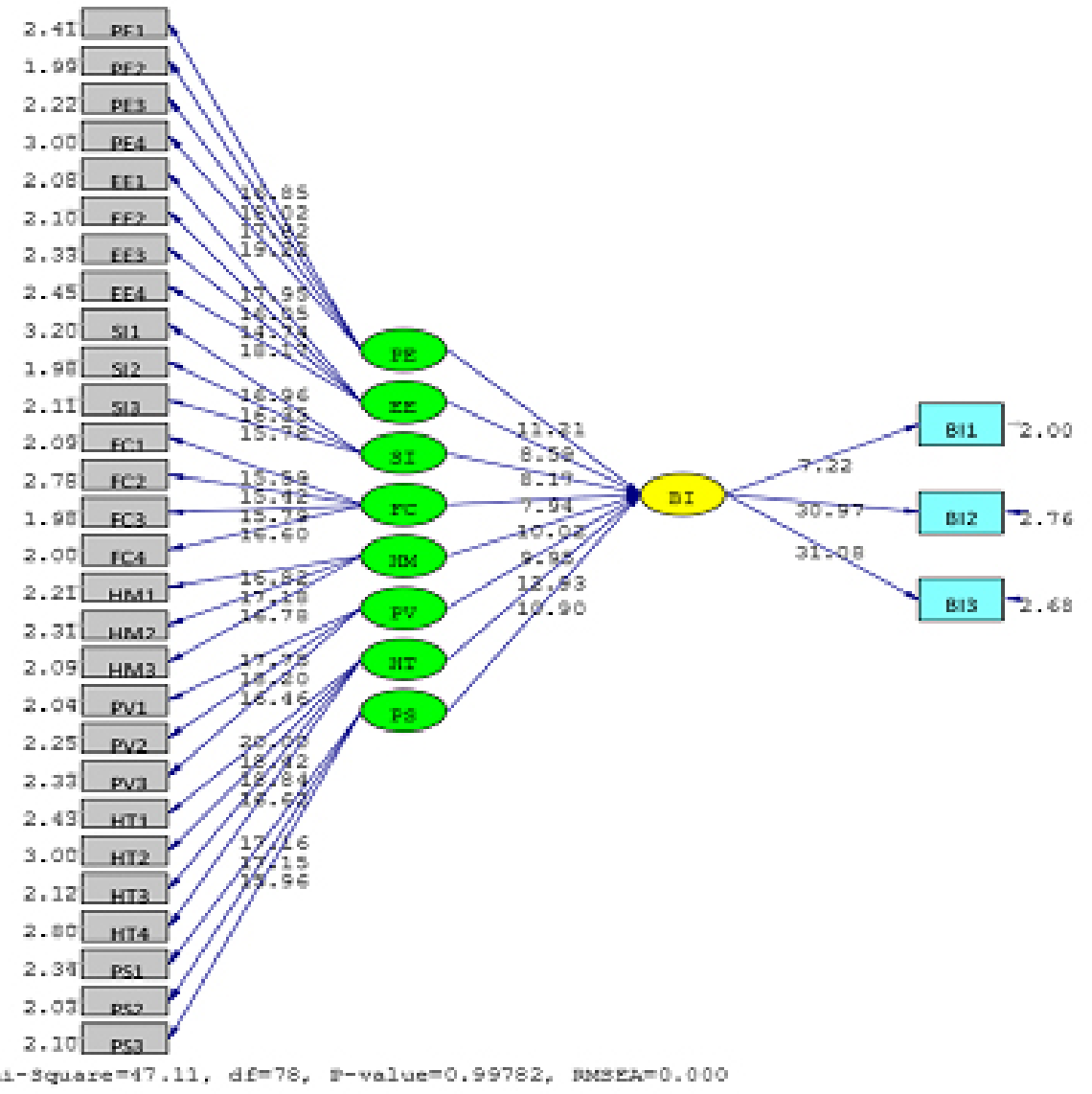

Gambar 3. T Hitung model intensi terhadap perilaku penggunaan teknologi digital payment 
Berdasarkan Tabel 7, dapat disampaikan bahwa masing-masing variabel, yaitu performance expectancy (harapan kinerja), effort expectancy (harapan usaha), social influence (pengaruh sosial), facilitating condition (kondisi fasilitasi), hedonic motivation (motivasi hedonisme), price value (nilai harga), habit (kebiasaan), dan perceived security (keamanan dirasakan) memiliki pengaruh yang signifikan terhadap variabel behavioral intention (intensi perilaku). Hasil dari penelitian ini sejalan dengan penelitian yang dilakukan oleh Venkatesh et al. (2012) yang menyatakan bahwa variabel performance expectancy (harapan kinerja), effort expectancy (harapan usaha), social influence (pengaruh sosial), facilitating condition (kondisi fasilitasi), hedonic motivation (motivasi hedonisme), price value (nilai harga), dan habit (kebiasaan) memengaruhi intensi perilaku. Hal yang sama dalam penelitian yang dilakukan oleh Junadi dan Sfenrianto (2015) bahwa perceived security (keamanan yang dirasakan) berpengaruh terhadap intensi perilaku. Secara umum, belum ada penelitian tentang wakaf uang atau wakaf melalui uang yang menggunakan metode UTAUT dalam mengukur intensi perilaku wakif gen Y.

Faktor yang paling besar pengaruhnya dalam mendorong intensi wakif gen $\mathrm{Y}$ dalam penggunaan teknologi digital payment untuk berwakaf uang atau wakaf melalui uang secara digital adalah habit (kebiasaan). Hasil uji menunjukkan nilai t hitung dari habit sebesar 12,93, nilai thitung lebih besar dari t tabel 1,96 artinya terdapat pengaruh signifikan antara habit terhadap behavioral intention, dan besar koefisien 0,59 bernilai positif artinya peningkatan habit akan mampu meningkatkan behavioral intention. Sehingga faktor penentu yang mendorong penggunaan teknologi digital payment untuk berwakaf uang atau wakaf melalui uang secara digital adalah adanya kebiasaan yang dilakukan oleh wakif gen Y dalam penggunaan layanan teknologi digital payment. Selanjutnya faktor lainnya yang berpengaruh signifikan berdasarkan prioritas adalah performance expectancy (harapan kinerja), perceived security (keamanan yang dirasakan), hedonic motivation (motivasi hedonis), price value (nilai harga), effort expectancy (harapan usaha), social influence (pengaruh sosial), dan facilitating condition (kondisi fasilitasi).

\section{Implikasi Manajerial}

Lembaga nazhir diharapkan mampu mengoptimalkan pemanfaatan teknologi digital yang bekerja sama dengan lembaga perbankan maupun lembaga fintech sebagai mitra layanan pembayaran digital yang paling banyak digunakan oleh wakifgen Y. Selain itu, bersinergi dengan connecting platfrom seperti pemanfaatan instagram ads juga dapat menjadi pilihan lembaga nazhir untuk dapat menjangkau lebih luas pada banyak pengguna instagram serta mengoptimalkan penggunaan layanan whatsapp blast sebagai media penyebaran informasi aktif dengan meningkatkan pengumpulan database yang dimilikinya. Dalam upaya optimalisasi kebiasaan baik bagi wakif gen Y dalam pemanfaatan teknologi digital payment untuk berwakaf, lembaga nazhir dapat secara terus menerus melakukan pemahaman secara intensif tentang kemudahan penggunaan pembayaran digital kapanpun dan dimanapun. Selain itu, dalam meningkatkan kepercayaan wakifgen $\mathrm{Y}$, lembaga nazhir perlu mensosialisasikan identitas kelembagaannya dengan mempublikasikan legalitas lembaga yang dimilikinya, program maanfaat penghimpunan, serta pelaporan secara terbuka. Mengingat dalam penelitian ini sebagian besar responden wakifgen Y adalah pekerja, maka lembaga nazhir juga dapat melibatkan wakif gen Y untuk turut berpartisipasi sebagai ambassador yang turut menyampaikan layanan program wakaf uang atau wakaf melalui uang serta pengalamannya dalam penggunaan teknologi digital payment untuk pembayaran wakaf secara digital kepada rekan kerjanya ataupun keluarga.

Tabel 7. Uji Hipotesis

\begin{tabular}{lccl}
\hline Hipotesis & T-hitung & Koefisien SLF & Kesimpulan \\
\hline $\mathrm{PE} \rightarrow \mathrm{BI}$ & 11,21 & 0,43 & Signifikan positif \\
$\mathrm{EE} \rightarrow \mathrm{BI}$ & 8,59 & 0,35 & Signifikan positif \\
$\mathrm{SI} \rightarrow \mathrm{BI}$ & 8,17 & 0,30 & Signifikan positif \\
$\mathrm{FC} \rightarrow \mathrm{BI}$ & 7,94 & 0,32 & Signifikan positif \\
$\mathrm{HM} \rightarrow \mathrm{BI}$ & 10,02 & 0,48 & Signifikan positif \\
$\mathrm{PV} \rightarrow \mathrm{BI}$ & 9,95 & 0,49 & Signifikan positif \\
$\mathrm{HT} \rightarrow \mathrm{BI}$ & 12,93 & 0,59 & Signifikan positif \\
$\mathrm{PS} \rightarrow \mathrm{BI}$ & 10,90 & 0,60 & Signifikan positif \\
\hline
\end{tabular}

Keterangan ${ }^{*}$ ) nilai t-hitung $\geq \mathrm{t}$-tabel 1,96 artinya pengaruh signifikan 
Lembaga nazhirjuga diharapkan dapat mengembangkan satu aplikasi layanan digital wakaf sebagai bentuk kesatuan pengembangan kolaboratif teknologi bersama dari masing-masing lembaga wakaf untuk penguatan platform pengumpulan dana wakaf secara institusional, dengan memperhatikan prioritas variabel yang memengaruhi secara signifikan penggunaan layanan pembayaran digital untuk berwakaf uang, yaitu habit (kebiasaan), performance expectancy (harapan kinerja), perceived security (keamanan yang dirasakan), hedonic motivation (motivasi hedonis), price value (nilai harga), effort expectancy (harapan usaha), social influence (pengaruh sosial), dan facilitating condition (kondisi fasilitasi).

\section{KESIMPULAN DAN SARAN}

\section{Kesimpulan}

Berdasarkan analisis deskriptif dapat disampaikan bahwa wakif gen Y perempuan sebagai mayoritas responden yang melakukan pembayaran wakaf uang atau wakaf melalui uang serta menggunakan teknologi digital payment untuk pembayaran wakaf. Pertimbangan utama responden wakif $Y$ dalam berwakaf uang atau wakaf melalui uang secara digital karena kemudahan dalam penggunaan metode pembayaran digital secara online untuk berwakaf kapanpun dan dimanapun, serta ketersediaan ragam pilihan metode pembayaran digital. Metode pembayaran wakaf uang atau wakaf melalui uang yang dominan dilakukan oleh responden wakif gen $\mathrm{Y}$ adalah dengan transfer via mobile banking serta via $e$-wallet. Hal ini menunjukkan bahwa sebagian besar responden sudah memanfaatkan layanan teknologi digital payment untuk pembayaran wakaf uang atau wakaf melalui uang. Sebagian besar responden wakif gen $Y$ memiliki pertimbangan dalam memilih lembaga nazhir berdasarkan legalitas lembaganya sebagai identitas resmi pengelolaan wakaf, serta adanya pelaporan wakaf uang atau wakaf melalui uang yang dilakukan secara terbuka.

Keseluruhan variabel yang diteliti, yaitu performance expectancy (PE), effort expectancy (EE), social influence (SI), facilitating condition (FC), hedonic motivation (HM), price value (PV), habit (HT), dan perceived security (PS) memiliki pengaruh signifikan positif dalam mendorong intensi wakif gen $\mathrm{Y}$ dalam menggunakan teknologi digital payment untuk pembayaran wakaf uang atau wakaf melalui uang.
Faktor yang paling besar dalam memengaruhi intensi wakif gen $\mathrm{Y}$ terhadap penggunaan teknologi digital payment untuk pembayaran wakaf uang atau wakaf melalui uang adalah habit (HT) yang menjadi kebiasaan bagi wakif gen $\mathrm{Y}$ dalam penggunaan layanan teknologi digital payment. Faktor selanjutnya yang berpengaruh signifikan berdasarkan prioritas adalah performance expectancy (harapan kinerja), perceived security (keamanan yang dirasakan), hedonic motivation (motivasi hedonis), price value (nilai harga), effort expectancy (harapan usaha), social influence (pengaruh sosial), dan facilitating condition (kondisi fasilitasi).

\section{Saran}

Saran bagi penelitian yang akan datang diharapkan dapat dilakukan kembali kepada wakif gen $\mathrm{Y}$ dengan melakukan perbandingan pada intensi wakif gen $\mathrm{Y}$ perempuan dan laki-laki yang memiliki intensitas tinggi terhadap perilaku penggunaan layanan mobile banking dan e-wallet untuk pembayaran wakaf uang atau wakaf melalui uang. Penelitian selanjutnya juga dapat diarahkan untuk dapat membahas fiturfitur pengembangan aplikasi layanan wakaf digital berdasarkan perspektif wakif gen Y serta keseluruhan variabel intensi yang memengaruhi penggunaan layanan wakaf digital. Selain itu, diharapkan untuk penelitian selanjutnya untuk dapat menganalisis perspektif wakif gen $\mathrm{Y}$ terhadap program digitalisasi penyaluran wakaf uang atau wakaf melalui uang yang dilakukan oleh lembaga nazhir.

\section{DAFTAR PUSTAKA}

Antonio MS. 2002. Bank Syariah dari Teori ke Praktek. Jakarta: Gema Insani Press.

Ascarya. 2016. Integrasi Keuangan Komersial dan Sosial Islam untuk Meningkatkan Stabilitas Sistem Keuangan dan Pembangunan Sosial Ekonomi.https://www.researchgate.net/ publication/315755916_Integrasi_Keuangan Komersial_dan_Sosial_Islam_untuk_ Meningkatkan_Stabilitas_Sistem_Keuangan_ dan_Pembangunan_Sosial-Ekonomi. [internet]. [20 Oktober 2019].

Berakon I, Agus MI, Nuha NH, Hikmatul FY. 2017. E-payment: inovasi layanan penghimpunan dan redistribusi wakaf uang berbasis online dalam percepatan pembangunan ekonomi Indonesia. Jurnal Al Qardh 5(1): 26-41.https://doi. 
org/10.23971/jaq.v2i1.824

[BPS] Badan Pusat Statistik. 2018. Statistik Gender Tematik : Profil Generasi Milenial Indonesia. https://www.kemenpppa.go.id/lib/uploads/ list/9acde-buku-profil-generasi-milenia.pdf. [9 Oktober 2019].

Deloitte Indonesia. 2019. Generasi Milenial dalam Industri 4.0: Berkah Bagi Sumber Daya Manusia Indonesia atauAncaman?.https://www2.deloitte. $\mathrm{com} /$ content/dam/Deloitte/id/Documents/aboutdeloitte/id-about-dip-edition-1-chapter-2-idsep2019.pdf. [20 Oktober 2020].

Didik M. 2019. 10 Aplikasi Pembayaran Digital yang Paling Populer Saat Ini. https://carisinyal.com/ jenis-pembayaran-digital-populer/. [17 Agustus 2019].

Fahruroji. 2019. Perbedaan Wakaf Uang dan Wakaf Melalui Uang. http://iwakaf.or.id/detail/post/84/ perbedaan-wakaf-uang-dan-wakaf-melaluiuang.html. [23 November 2020].

Hair J F, William CB, Barry JB, Rolph EA. 2014. Multivariate Data Analysis. Seventh Edition. United States: Pearson.

Igbaria M, NancyZ, PaulC,Angele LMC. 1997.Personal computing acceptance factors in small firms: a structural equation model. MIS Quarterly 21(3): 279 - 305. https://doi.org/10.2307/249498

Junadi, Sfenrianto. 2015. A model factors influencing consumer's intention to use e-payment system in Indonesia. Procedia Computer Science 59(2015): 214-220. https://doi.org/10.1016/j. procs.2015.07.557

[KNKS] Komite Nasional Ekonomi dan Keuangan Syariah. 2019. Optimalisasi Wakaf Produktif untuk Kesejahteraan Umat. https://knks. go.id/storage/upload/1569306459-KNKS\%20 Edisi\%20Keempat\%20-\%20September.pdf. [20 Oktober 2020].
Kotler P, Hermawan K, Iwan S. 2017. Marketing 4.0 Bergerak dari Tradisional ke Digital. Jakarta: PT Gramedia Pustaka Utama.

Sepryna A, Nissa GR. 2013. Pengaruh sikap, norma subjektif, dan kontrol perilaku yang dirasakan terhadap niat, serta pengaruh niat terhadap kepatuhan membayar zakat penghasilan. [tesis]. Depok: Universitas Indonesia.

Suganda AD. 2014. Konsep wakaf tunai. Slamiconomic: Jurnal Ekonomi Islam 5(2): 1-15. https://doi. org/10.32678/ijei.v5i2.25

Trihasta D, Julia F. 2008. E-Payment sistem. Proceeding, Seminar Ilmiah Nasional Komputer dan Sistem Intelijen (KOMMIT 2008).

Venkatesh V, Michael GM, Gordon BD, Fred DD. 2003. User acceptance of information technology: toward a unified view. MIS Quarterly 27(3): 425-478. https://doi.org/10.2307/30036540

Venkatesh V, James YLT, Xin X. 2012. Consumer acceptance of information technology: extending the unified theory of acceptance and use of technology. MIS Quarterly 36(1): 157-178. https://doi.org/10.2307/41410412

Wijanto SH. 2008. Structural Equation Modeling dengan Lisrel 8.8 Konsep dan Tutorial. Yogyakarta: Graha Ilmu.

Yoepitasari AH, Imroatul K. 2018. Analisis pengaruh kualitas produk, promosi, dan desain produk terhadap keputusan pembelian dengan citra merek sebagai variabel intervening. Jurnal Studi Manajemen Organisasi 15(2018): 55-69.

Zuhdi, Budi S, Hadi S. 2016. Perbandingan pendugaan parameter koefisien struktural model melalui sem dan pls-sem. Journal of Mathematics and Its Applications 15(2): 11-22. https://doi. org/10.29244/jmap.15.2.11-22 